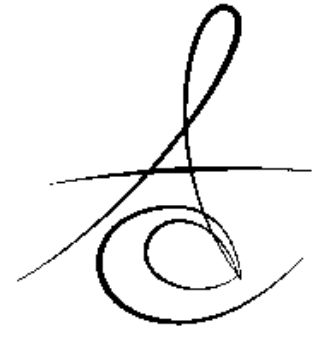

Makale Kodu/Article code: 2082

Makale Gönderilme tarihi: 26.01 .2015

Kabul Tarihi; 24.03.2015

\title{
FARKLI YÜZEY BİTİM İŞLEMLERİNİN FELDSPATİK PORSELENİN YÜZEY PÜRÜZLÜLÜĞÜNE ETKİsí
}
EFFECTS OF DIFFERENT SURFACE TREATMENTS ON SURFACE ROUGHNESS OF FELDSPATHIC PORCELAINS

\author{
Dt. Faruk EMİR*
}

Doç. Dr. Simel AYYILDIZ*

Yrd. Doç. Dr. Cem ŞAHİN**

\section{ÖZET}

Amaç: Bu çalışmanın amacl; feldspatik porselene 4 farklı yüzey bitim ve polisaj işlemi uygulanmasının yüzey pürüzlülüğüne etkisini karşılaştırmalı olarak değerlendirmektir.

Materyal ve Metot: Altmış adet disk şeklinde $(5.3 \times 2.2 \mathrm{~mm})$ feldspatik porselenden örnekler üretici talimatlarına göre hazırlandı. Tüm örneklerin, kalından inceye doğru azalan gren çapına sahip elmas frezlerle tesviyesi yapılarak glaze işlemi uygulandı. Örnekler, her grupta 15 adet olacak şekilde rastgele dört gruba ayrıldı. İlk gruba sadece frezle pürüzlendirme (Grup F), ikinci gruba frez ve porselen polisaj lastiği (Grup FL), üçüncü gruba, frez ve keçe ile elmas pasta (Grup FP), dördüncü gruba ise frez ve tekrar glaze yapıldı (Grup

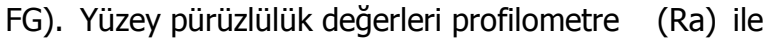
ölçüldü. Ayrıca taramalı elektron mikroskobu (SEM) ile yüzey incelemesi yapılarak profilometre verileriyle sonuçlar karşılaştırıldı.

Bulgular:Polisaj metotları yüzey pürüzlülüğü açısından değerlendirildi ve gruplar arasında istatistiksel olarak anlamlı fark bulundu. En düşük Ra değeri Grup FG' de görülürken, en yüksek Ra değerini Grup $F$ göstermiştir. Bu değerler SEM görüntüleriyle karşılaştırıldığında benzer sonuçlar elde edilmiştir.

Sonuç: Feldspatik porselene uygulanan yüzey işlemlerinde en pürüzsüz yüzey glaze işlemiyle elde edilmiştir. Bunu sırasıyla Grup FP ve Grup FL izlemiştir. Sadece frez uygulaması yapılan örneklerde ise en yüksek yüzey pürüzlülüğü değerleri ölçülmüştür.

Anahtar kelimeler: Polisaj sistemleri, yüzey pürüzlülüğü, elmas cila pastası

\section{ABSTRACT}

Aim: The purpose of this study was to evaluate the effect of four different surface finishing and polishing methods on the surface roughness of feldspathic ceramic materials.

Material and Method: Sixty disc-shaped (5.3x2.2 $\mathrm{mm}$ ) feldspathic porcelain specimens were fabricated according to manufacturer's recommendations. All specimens were grinded by finishing diamond burs from coarse to fine grained, respectively. After grinding process all specimens were glazed. Porcelain discs were divided into 4 groups $(n=15)$ randomly. In first group, specimens were only grinded with finishing diamond burs (Group F). In the second group, specimens were grinded and polished with rubber porcelain polishers (Group FL). In the third group, specimens were grinded and polished with diamond paste and buff disks. (Group FP). The specimens of the last group were grinded and glazed (Group FG). The surface roughness was evaluated with profilometer. Also the surface of the porcelain discs were examined with scanning electron microscope (SEM) and data were compromised with the profilometer.

Results: Polishing methods were evaluated for surface roughness and the difference between groups was found statistically significant. FG group showed minimum $R$ a values. $F$ group was showed maximum Ra values and this result was validated by surface evaluation via SEM.

Conclusion: After the treatments applied to the feldspathic porcelain, the smoothest surface was obtained by glazing process. Group FP and Group FL follows glaze process, respectively. Only bur treated group showed maximum surface roughness values.

Key words: Polishing systems, surface roughness, diamond polishing paste.

\footnotetext{
* GATA Diş Hekimliği Bilimleri Merkezi Protetik Diș Tedavisi Anabilim Dalı

** Hacettepe Üniversitesi Sağlık Hizmetleri Meslek Yüksekokulu Diş Protez Teknolojisi
} 


\section{GİRIŞ}

Porselen restorasyonlar, doğal diş yapısına yakın estetiğe sahiplerdir. Her geçen gün hastaların estetik taleplerinin artması nedeniyle bu tip restorasyonların diş hekimliğinde kullanımı gittikçe yaygınlaşmıştır. ${ }^{1}$ Dental porselenler, mükemmel biyouyum ve dayanıklılık göstermekle birlikte translusentlik, renk ve yoğunluk gibi gelişmiş özellikleri nedeniyle estetik görünüme sahiptirler. ${ }^{1,3}$ Günümüzde, sabit protez uygulamalarında kullanılan feldspatik porselen, yumuşak dokular tarafından iyi tolere edilmesi ve üstün estetik özelliklerinden dolayı tek başına ya da veneerleme materyali olarak sıklıkla tercih edilir hale gelmiştir. ${ }^{4-6}$

Porselen ile üretilen protetik restorasyonlarda, restorasyonun bitimini takiben, konturların düzeltilmesi veya daha estetik bir görünüm için ağız içinde yapılan düzenlemeler, porselen yüzeyinde pürüzlü alanların oluşmasına sebebiyet vermektedir. Bu da; plak birikimi, gingival inflamasyon ve yumuşak doku yanıtında artış gibi istenmeyen sonuçlara yol açabilmekte- dir. ${ }^{7-11}$ $\mathrm{Bu}$ yüzden, bakteri retansiyonunun azaltıl- ması amacıyla genelde pürüzsüz ve parlak yüzeylere ihtiyaç duyulur. ${ }^{12}$ Aynı zamanda pürüzlü yüzeylerin, komşu ve karşılıklı dişlerde abrazyona ve renklenmeye de sebep olduğu bilinmektedir. ${ }^{8}$ Klinik başarıyı arttır- mak, hasta konforuna katkı sağlamak, optimum estetik ve oral hijyeni sağlayabilmek için restoratif materyal- lerin yüzey pürüzlülüğü minimuma indirilmelidir. ${ }^{13}$

Geçmişteki çalışmalarda porselenlerin; amalgam, kompozit rezin ve metal dökümlerle karşılaştırıldıklarında daha az bakteriyal ve glukan adezyonu gösterdikleri belirtilmiştir. ${ }^{14}$ Gingival dokular, porselenden yapılmış bir kuron protezine diğer materyallere göre en olumlu yanıtı vermektedir. Ancak bu durumun devam edebilmesi için, bitirilmiş porselen restorasyonun uyumlama sırasında yapılan aşındırma işlemi sonucu ortadan kalkan ince glaze tabakasının tekrar oluşturulması veya polisajlanması gerekmektedir. ${ }^{13}$ Porselenin tekrarlayan fırınlamalar sonucu hem optik hem de yapısal özelliğinde değişiklikler olması nedeniyle yüzeyin pürüzsüz hale getirilebilmesi için daha farklı bitirme işlemleri uygulanmaktadır. Günümüzde bu amaç için kullanıma sunulmuş birçok farklı ticari ürün bulunmaktadır. ${ }^{11,15,16}$ Böylece porselenin yapısal özellikleri bozulmadan, doğal diş minesi gibi görünümünü koruyarak farklı polisaj ve bitirme işlemleri uygulanabilmektedir. $^{17}$
Günümüzde, hasta başında uygulanan bitirme işlemleri materyal özelliğine göre değişmekle birlikte; lastik ve silikon diskler, keçeler, aşındırıcı taşlar ve elmas pastalar gibi materyaller kullanılmaktadır. ${ }^{18,19}$ Bütün bu işlemler; restorasyonların uzun dönem başarısının temini, klinik açıdan enfeksiyon kontrolünün sağlanması, daha iyi bir oral hijyen elde edilmesi ve son olarak hekim açısından etkili ve hızlı yöntemler olmaları sebebiyle kullanılmaktadır.

Bu nedenle, yaptığımız çalışmada, sabit protezlerin yapımında veneerleme porseleni olarak kullanılan feldspatik porselen, 4 farklı yüzey işlemine tabi tutulmuş ve yüzey pürüzlülük değerleri ölçülmüştür. Elde edilen sonuçların klinik uygulamalara ışık tutacağı düşünülmüştür.

\section{MATERYAL VE METOD}

Hazırlanan feldspatik örnekler ve yüzey işlemlerinde kullanılan materyaller Resim 1' de gösterilmiştir.

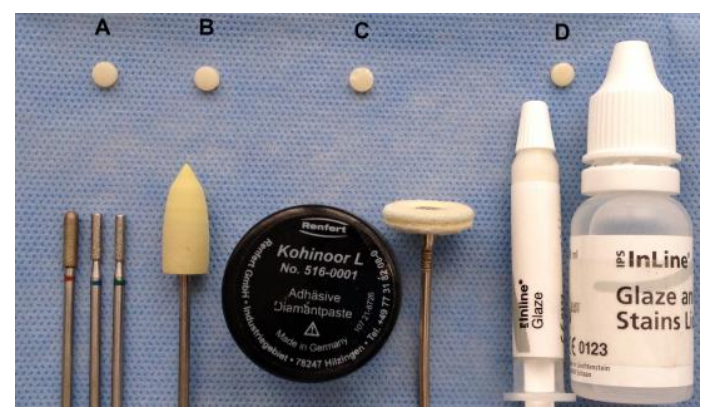

Resim 1. Hazırlanan feldspatik örnekler ve yüzey işlemlerinde kullanilan materyaller.

A. Grup F, B. Grup FL, C. Grup FP, D. Grup FG

Porselen Örneklerin Hazırlanması: Altmış adet disk şeklindeki $(5.3 \times 2.2 \mathrm{~mm})$ örnek, metal kalıp kullanılarak feldspatik porselenden (IPS Inline, Ivoclar Vivadent Schaan, Liechtenstein) üretildi. Örneklerin yapımında kondensasyon tekniği kullanıldı, her bir örnek için aynı miktarda porselen tozu ve likidi kullanılarak, aynı teknisyen tarafından hazırlandı. Hazırlanan örnekler porselen fırınında, (Programat P20, Ivoclar Vivadent, Schaan, Liechtenstein) dentin programında öncelikle $280{ }^{\circ} \mathrm{C}^{\prime}$ de dakikada $60{ }^{\circ} \mathrm{C}^{\prime}$ lik artışla yaklaşık 5 dakika vakum altında $915{ }^{\circ} \mathrm{C}^{\prime}$ ye kadar ısıtıldı, $915{ }^{\circ} \mathrm{C}^{\prime}$ de $1 \mathrm{dk}$ kalarak pişim işlemi tamamlandı. Fırın ISıSı $220{ }^{\circ} \mathrm{C}^{\prime}$ ye indiğinde örnekler çıkarıldı ve oda sıcaklığında soğumaya bırakıldı. Her dentin porseleni ilavesinde fırınlama ISISI $5^{\circ} \mathrm{C}$ düşecek 
şekilde pişim işlemi yapıldı. Hazırlanan örnekler dijital kumpas (DT-100, Instro Endüstriyel Ölçüm Ürünleri Ltd. Şti., İstanbul, Türkiye) kullanılarak ölçüldü, aynı kalınlık ve çapta olması sağlandı.

Tüm porselen disklerin tesviyeleri tur motoru (W\&H Perfecta 600, Bürmoos, Austria) ile 10000 devir hızında, farklı gren kalınlığında elmas frezler (kalından grenden inceye doğru) kullanılarak yapıldı. Örnekler tesviye işleminden sonra $15 \mathrm{dk}$ boyunca içinde distile su bulunan ultrasonik temizleyicide (Ultrasonic Cleaner VGT-1740QTD, Guangzhou Sunlight Medical Equipment Co. Ltd., Guangdong, China) bekletildi ve oda ısısında kurumaya bırakıldı. Daha sonra tüm örneklere $890{ }^{\circ} \mathrm{C}^{\prime}$ de vakum altında glaze yapıldı. Örnekler rastgele 4 gruba ayrıldl; ilk gruptaki örneklerde porselen disklerin yüzeyi sadece frezlenerek glaze tabakası kaldırıldı (Grup F) $(n=15)$. İkinci gruptaki örnekler önce frezlendi ve daha sonra porselen polisaj lastiği ile yeniden parlatıldı (Grup FL) ( $n=15)$. Üçüncü gruba, öncelikle frez, daha sonra keçe ile elmas pasta (Grup FP) uygulandı ( $n=15)$. Dördüncü gruba ise, yine önce frez uygulandı, daha sonra tekrar glaze yapıldı (Grup FG) $(n=15)$.

Hem porselen lastiği hem de elmas pasta uygulanarak yapılan polisaj işlemi; aynı hekim tarafından, tur motoru kullanilarak 60sn boyunca 10000 rpm' de porselen yüzeyleri parlak bir hal alıncaya kadar yapıldı. Polisaj işleminde elmas pasta olarak Kohinoor L (Renfert GmbH, Hilzingen, Germany) kullanıldı.

Yüzey Pürüzlülük Ölçümleri: Ölçümlerden önce profilometre (Time TR100, Phynix GmbH \& Co., Köln, Germany) kalibre edildi. Tüm yüzey pürüzlülük ölçüm değerleri örneklerin merkezinden alındı. Her örnek için 3'er ölçüm yapıldı ve örneklerin genel yüzey karakteristiklerini belirlemek için bu ölçümlerin ortalaması alındı. Elde edilen pürüzlülük değerleri $(\mathrm{Ra})$ profilometre tarafından ölçülen ortalama yüzey pürüzlülük değerlerini göstermektedir. Düşük Ra değerleri daha pürüzsüz bir yüzeyi belirtmektedir.

Taramalı Elektron Mikroskobu (SEM) İncelemesi: Her gruptan dörder örnek rastgele seçildi. Seçilen örnekler taramalı elektron mikroskobu çalışması öncesi platin alaşımı ile kaplandı. Örnekler yüzey pürüzlülüğünün değerlendirilmesi amacıyla SEM'de (JSM 6400, Jeol Ltd., Tokyo, Japan) X1000 ve X3000 büyütmelerde incelendi. SEM ile her örneğin yüzeyinden elde edilen görüntüler ve Ra değerleri karşılaştırıldı.
İstatistiksel değerlendirme: Gruplar arası farlılık olup olmadığı One-Way Anova Testi ile belirlendi. Gruplar arası farkın belirlenmesine yönelik çoklu karşılaştırmalarda ise Bonferroni düzeltmeli Post-Hoc test kullanıldı. Tüm istatistiksel çalışmalarda IBM SPSS programı (SPSS 15.0, SPSS Inc., Chicago, IL, USA) kullanıldı ve $p<0,05$ istatistiksel olarak anlamlı kabul edildi.

\section{BULGULAR}

Profilometre ölçümlerine göre elde edilen pürüzlülük değerlerinin ortalaması Tablo $1^{\prime}$ de gösterildiği gibidir. Buna göre en düşük Ra değeri Grup FG'de bulunurken, en yüksek değeri Grup $F$ göstermiştir.

One-way ANOVA test sonuçlarına göre porselen polisaj metotları arasındaki fark istatistiksel olarak anlamlı bulundu $(p<0.05)$. Yapılan Bonferroni testi tüm gruplara ait pürüzlülük değerlerinin birbirinden farklı olduğunu ortaya koydu (Tablo 2 ).

Tüm gruplardan elde edilen SEM görüntüleri incelendiğinde, $F$ grubunda, girintili çıkıntılı düzensiz alanlar gözlenmiştir. FP grubunda ise $F$ grubundaki girinti ve çıkıntıların azaldığı, keskin hatların yuvarlaklaştı̆ı̆ görülmektedir. FG grubunda ise $F$ ve FP gruplarına göre çok daha düzgün alanlar tespit edilmiştir (Resim 2).

Tablo 1. Yüzey işlemlerine göre ortalama ve standart sapma değerleri

\begin{tabular}{|l|c|c|c|}
\hline \multicolumn{1}{|c|}{ Gruplar } & $\begin{array}{c}\text { Örnek } \\
\text { SayıSI }\end{array}$ & $\begin{array}{c}\text { Ortalama } \\
\text { (Ra }\end{array}$ & $\begin{array}{c}\text { Standart } \\
\text { Sapma }\end{array}$ \\
\hline F (frez) & 15 & 1.48 & 0.22 \\
\hline FL (frez+lastik) & 15 & 1.02 & 0.18 \\
\hline FP (frez+pat) & 15 & 0.64 & 0.21 \\
\hline FG (frez+glaze) & 15 & 0.38 & 0.14 \\
\hline Toplam & 60 & 0.88 & 0.45 \\
\hline
\end{tabular}

*Ra değerleri $\mu \mathrm{m}$ olarak verilmiştir.

Tablo 2. Gruplar arası farkın belirlenmesine yönelik çoklu karşılaştırmada Bonferroni düzeltmeli Post-Hoc Test sonuçları

\begin{tabular}{|c|c|c|c|c|}
\hline Gruplar & $\mathrm{F}$ & $\mathrm{FL}$ & $\mathrm{FP}$ & $\mathrm{FG}$ \\
\hline $\mathrm{F}$ & - & $0.46\left(^{*}\right)$ & $0.83\left(^{*}\right)$ & $1.10\left(^{*}\right)$ \\
\hline $\mathrm{FL}$ & $-0.46\left(^{*}\right)$ & - & $0.37\left(^{*}\right)$ & $0.64\left(^{*}\right)$ \\
\hline $\mathrm{FP}$ & $-0.83\left(^{*}\right)$ & $-0.37\left(^{*}\right)$ & - & $0.26\left(^{*}\right)$ \\
\hline $\mathrm{FG}$ & $-1.10\left(^{*}\right)$ & $-0.64\left(^{*}\right)$ & $-0.26\left(^{*}\right)$ & - \\
\hline
\end{tabular}

* Ortalama farklılıkların anlamlı olduğu değer. $p<0.05$ 


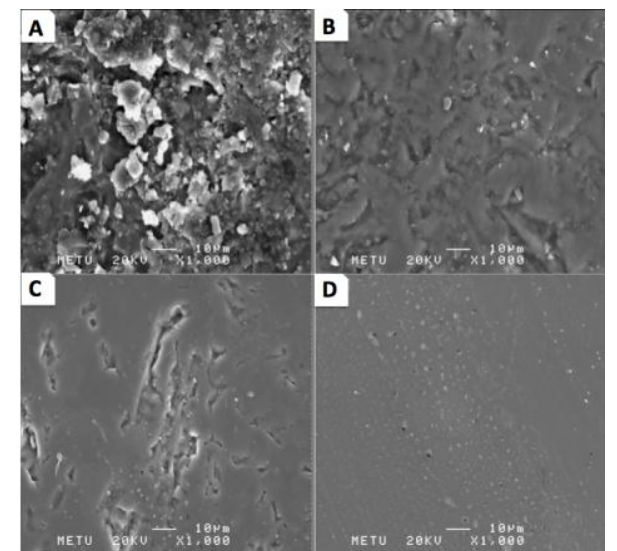

Resim 2. Yüzey işlemleri sonrası örnek yüzeylerinden alınan x1000 büyütmedeki SEM görüntüleri

A. Grup F, B. Grup FL, C. Grup FP, D. Grup FG

\section{TARTIŞMA}

Çalışmamızda porselen bitim ve polisaj işlemlerinde yaygın olarak kullanılan elmas frez, porselen lastiği, elmas pasta ve glaze uygulamaları feldspatik porselenin yüzey pürüzlülüğü açısından karşılaştırımıştır. Elde edilen verilere göre, uyumlama sonrası yapılan polisaj işlemleri ile glaze işlemi sonrasındaki kadar pürüzsüz yüzeyler elde edilememektedir.

Sabit protetik tedavilerde oklüzal uyumlamalar genelde simantasyon öncesi yapılmasına rağmen kimi zaman simantasyon sonrasında da uyumlamalara gereksinim duyulabilmektedir. Oklüzal uyumlama sonrasında oluşan pürüzlü porselen yüzeylerin olumsuz etkileri birçok araştırmaya konu olmuştur. Ayrıca bu pürüzlü yüzeylerin ortadan kaldırılabilmesi için çeşitli bitirme ve polisaj işlemlerinin etkinlikleri de birçok çalışmada tartışılmıştır. Polisajlanmış ve glazelenmiş porselen örneklerin yüzey karakteristikleri ile ilgili yapılan çalışmaların sonuçları birbiriyle çelişebilmekte$\operatorname{dir}^{13,20}$

Çeşitli araştırmacıların yaptıkları çalışmalarda uyumlama sonrası yapılan polisaj işlemleri ile glaze işlemindeki kadar pürüzsüz yüzeyler elde edilemeyebileceği bildirilmiştir. ${ }^{20-22}$ Bizim çalışmamızda da önceki çalışmalarla benzer sonuçlar elde edilmiş ve farklı polisaj ve bitim işlemlerinin glaze işleminin yerini tutamadığı görülmüştür. Ward ve ark. ${ }^{17}$ ise polisaj kitleriyle elde edilen yüzeylerin glaze işlemi sonrası elde edilen yüzeylerden daha düzgün olduğunu bildirmişlerdir. Bottino ve ark. $^{23}$ ise elmas frezlerle bitirme işleminin ardından elmas pastayı keçe diske emdirmeden porselen yüzeyine uyguladıktan sonra keçe diskle polisajlama işlemi yapmışlar ve glaze işlemine yakın pürüzlülük değerleri saptamışlardır. Çalışmamızın sonuçlarında elmas pasta kullanılan Grup FP ile Grup FG arasında pürüzlülük açısından anlamlı fark bulunmuş ve SEM görüntülerinde de Grup FP'nin yüzeyi Grup FG'den daha pürüzlü izlenmiştir. Çalışmamızda, Bottino ve ark. ${ }^{23}$ 'nın belirttiği gibi glaze grubuna yakın değerler elde edilememiş olmasının sebebi Grup FP'de, üretici firmanın talimatları doğrultusunda elmas pastanın keçe diske emdirilerek polisaj işlemi yapılması olabilir.

Aykent ve ark. ${ }^{11}$ ise farklı porselen materyallerinde lastik polisaj kiti uygulanan ve glaze yapılan gruplar arasında anlamlı bir fark bulamamıştır. Bizim çalışmamızda ise tüm gruplar arasında yüzey pürüzlülük değerleri açısından anlamlı farklılar görülmüş ve bu bulgular SEM görüntüleriyle de desteklenmiştir.

Porselen yüzeylerinde yapılan uyumlama işlemleri ile porözite, yarık ve çatlak gibi yapılar oluşur. ${ }^{7}$ Uyumlama sonucu oluşan pürüzlü yüzey, karşıt arktaki mine veya restoratif materyalin aşınmasını arttırabilir. ${ }^{7,9,20}$ Bu yüzden glaze'i bozulmuş porselen yüzeyleri, karşıt dentisyondaki aşınmayı önlemek ve plak retansiyonunu en aza indirmek için düzgünleştirilmelidir. ${ }^{3,24}$ Heintze ve ark. ${ }^{25}$ yaptıkları çalışmada; glaze işlemi yapılmış düz yüzeyli örneklerde polisajlanmış düz yüzeyli örneklere göre daha fazla aşınma görülürken, kuron şeklinde hazırlanmış örneklerde ise bunun tam tersi görülmüştür. Yu ve ark. ${ }^{26}$ ise bazı klinik uygulamalar ile oklüzal kuvvetlerin kontrol altına alınarak dental porselen restorasyonlarının korunabileceğini söylemişlerdir. Ayrıca porselen materyalindeki aşınmaların sadece yüzeyin pürüzlülüğüne değil aynı zamanda oklüzal kuvvetlere, materyal özelliklerine ve tükürüğün kayganlaştırıcı bir rol oynamasına da bağlı olabileceğini bildirmişlerdir.

Porselen restorasyonun yüzeyi yeterli düzeyde pürüzsüz hale getirilmediğinde, yüzeyde daha fazla plak birikimi olduğu bilinmektedir. ${ }^{27}$ Glazelenmiş yüzeyin serbest yüzey enerjisi, glazelenmemiş porselen materyalinden fazladır. Bu sebeple glazelenmemiş yüzeyde bakteri birikimi anlamlı bir şekilde artabilmektedir. ${ }^{28}$ Glazelenmemiş yüzey tükürük ile temas ettiğinde, porselen içindeki katyonik bölgelerle tükürük proteinlerinin anyonik grupları bağ yapar. Bu da yüzeyde selektif bakteriyal adsorbsiyona sebep olmaktadır. ${ }^{29}$ Yapılan bir in-vivo çalışmada erken plak formasyo-

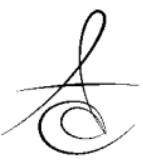


nunda, yüzey pürüzlülüğü ve serbest yüzey enerjisinin etkisi değerlendirilmiştir. Yüksek serbest yüzey enerjisine sahip materyallerde, düşük serbest yüzey enerjisine sahip materyallere göre daha az plak birikimi görülmektedir. Yüzey pürüzlülüğü, plak birikiminde serbest yüzey enerjisinin etkisini azaltabilmektedir. ${ }^{30}$ Yüzey pürüzlülüğünün polisaj işlemiyle azaltılması sonucu plak formasyonu ve matürasyonu dramatik bir şekilde azalmaktadır. Serbest yüzey enerjisinin polisajla düşürülmesi; plak oluşum oranını ve plak retansiyonunu azaltmakta ayrıca materyal yüzeyinde kolonize olan spesifik organizmaları olumsuz yönde etkilemektedir. ${ }^{31,32} \mathrm{Bu}$ durumda, yaptığımız çalışmanın sonuçları göz önüne alındığında en düşük Ra değerinin görüldüğü Grup FG porselen yüzeyi, ağız içi ortamda bakteri kolonizasyonunun minimum seviyede olması için ideal kabul edilebilirken, buna en yakın değere sahip porselen yüzeyi Grup FP'de görülmüştür. Bu nedenle klinik ortamda glazeli porselen yüzeyinin herhangi bir nedenle yüzeyi pürüzlendirilirse, yüzeyin bu şeklide bırakılması yerine en azından elmas pasta kullanılarak parlatılması hem karşıt dentisyonu aşınmadan koruyacak, hem de bakteri kolonizasyonunu minimum seviyede tutmaya yardımcı olacaktır.

Polisaj işleminin yanı sıra, bu işlemi uygulama tekniği de porselenin dayanıklıığını etkilemektedir. Yapılan in-vitro bir çalışmada, porselen farklı kuvvetler altında ve farklı polisaj sistemleriyle polisajlanmıştır. ${ }^{33}$ Polisaj hızının 10000 rpm' den 20000 rpm' ye çıkarmanın porselen materyalinin eğilme dayanıklıı̆ııı anlamlı bir şekilde düşürdüğü gözlemlenmiştir. ${ }^{33} \mathrm{Bu}$ yüzden çalışmamızda bitim ve polisaj işlemleri için kullanılan el aletinin devir hızı 10000 rpm olarak seçilmiştir.

Dişlerin lingual veya okluzal yüzeyleri gibi anatomik yapılarda lastik polisaj aletleri, ıslak keçe ve farklı pastalar gibi materyallerin kullanımı bu yüzeylerin polisajı için daha uygundur. ${ }^{18,34} \mathrm{Bu}$ nedenle çalışmamızda, yüzey bitim işlemlerinde; elmas frez, porselen polisaj lastiği ve keçe disk ile uygulanan elmas pasta, devir hızı ayarlanabilen döner aletlerle porselen yüzeylerine uygulanmıştır.

Yüzey pürüzlülüğü temaslı ve temassız ölçüm metotlarıyla yapılmaktadır. Temassız ölçüm yapanlar ışık veya lazer, sıkıştırılmış hava ve SEM ile yüzey profilini ortaya çıkarırlarken temaslı ölçümde profilometreler kullanılmaktadır. ${ }^{35}$ Çalışmamızda kullandığımız Ra değeri, bir cismin tüm yüzeyinin pürüzlülüğünü belirtir ve ölçüm yapılan mesafe boyunca elde edilen pürüzlülük profilinin aritmetik ortalaması olarak tanımlanır. ${ }^{13}$ Pek çok çalışmada da bu değer, porselen örneklerin yüzey yapısını tanımlamak amacıyla, profilometre kullanılarak elde edilmiştir.3,35 Çalışmamızda yüzey pürüzlülüğünü niceliksel olarak değerlendirebilmek amacıyla profilometre cihazı kullanılmıştır.

Araştırmalar arasındaki uygulama farklılıkları, farklı polisaj ve porselen sistemlerinin kullanılması elde edilen farklı sonuçların bir açıklaması olabilir. ${ }^{20}$ Yapılan çalışmalarda farklı porselen yapılarında polisaj işlemlerinin oluşturduğu farklılıklar araştırımış ve sonuçlar buna göre değerlendirilmiştir. ${ }^{13,18,36,37}$ Çalışmamızda, klinikte yaygın olarak kullanılan feldspatik porselen kullanılmıştır.

Örneklerin tek çeşit porselenden yapılması, bu örneklerin gerçek restorasyonlar yerine disk şeklinde hazırlanmış olması ve karşıt dentisyonun aşındırıcı etki- sinin incelenmemiş olması mevcut çalışmanın sınırıılıklarıdır.

\section{SONUÇ}

Çalışmamızda; uygulanan polisaj yöntemleri arasında en düşük yüzey pürüzlülük değerleri glaze işlemi yapılan FG grubunda görülmüştür. FP grubunda ise yüzey pürüzlülük değerleri, FG grubundan daha yüksek ve diğer gruplara göre ise daha düşük çıkmıştır. En yüksek pürüzlülük değerleri ise $F$ grubunda görülmüştür.

Bitirme ve polisaj işlemleri porselenlerin yüzey pürüzlülüğünü azaltmada önemli bir rol oynamaktadır. Bu yüzden uyumlama yapılan bütün porselen restorasyonlara mutlaka tekrar glaze yapılmalı veya bitirme işlemine tabi tutulmalıdırlar.

\section{KAYNAKLAR}

1. Kawai K, Urano M, Ebisu S. Effect of surface roughness of porcelain on adhesion of bacteria and their synthesizing glucans. J Prosthet Dent 2000; 83: 664-7.

2. Anusavice KJ, Shen C, Rawls HR. Phillips' Science of Dental Materials. 12 ed.; Philadelphi;, WB Saunders Co: 2013. p 419-20.

3. Sarikaya I, Güler AU. Effects of different polishing techniques on the surface roughness of dental porcelains. J Appl Oral Sci 2010; 18: 10-6.

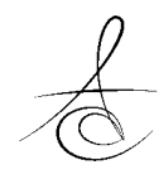


4. McLean JW. Ceramics in clinical dentistry. Br Dent J 1988, 164: 187-94.

5. Williamson RT, Kovarik RE, Mitchell RJ. Effects of grinding, polishing, and overglazing on the flexure strength of a high-leucite feldspathic porcelain. Int J Prosthodont 1996; 9: 30-7.

6. Atay A, Oruç S, Özen J, Sipahi C. Effect of accelerated aging on the color stability of feldspathic ceramic treated with various surface treatments. Quintessence International 2008. 39: 603-9.

7. Al Wahadni A, Martin DM. Glazing and finishing dental porcelain: A literature review. J Can Dent Assoc 1998; 64 :580-3.

8. Jagger DC, Harrison A. An in-vitro investigation into the wear effects of unglazed, glazed, and polished porcelain on human enamel. J Prosthet Dent 1994; 72: 320-3.

9. Schlissel ER, Newitter DA, Renner RR, et al. An evaluation of post adjustment polishing techniques for porcelain denture teeth. J Prosthet Dent 1980; 43: 258-65.

10. Wright MD, Masri R, Driscoll CF, et al. Comparison of three systems for the polishing of an ultra-lowfusing dental porcelain. J Prosthet Dent 2004; 92: 486-90.

11. Aykent $F$, İnan Ö, Üşümez $A$, et al. Evaluation of surface roughness of ceramics following different polishing methods. G.Ü. Diş Hek Fak Derg 2001; 18: 63-7.

12. Craig RG, Powers JM, Wataha JC. Dental Materials: Properties and manipulation. Saint Louis; Mosby: 2004.

13. Tholt $B$, Miranda-Júnior WG, Prioli $R$, et al. Surface roughness in ceramics with different finishing techniques using atomic force microscope and profilometer. Operative Dentistry 2006; 31: 442-9.

14. Kawai K, Urano M. Adherence of plaque components to different restorative materials. Operative Dentistry 2001; $26: 396-400$.

15. Al Wahadni A, Martin DM. An in vitro investigation into the wear effects of glazed, unglazed and refinished dental porcelain on an opposing material. J Oral Rehabil 1999; 26: 538-46.

16. Hulterström AK, Bergman M. Polishing systems for dental ceramics. Acta Odontol Scand 1993; 51: 229-34.
17. Ward MT, Tate WH, Powers JM. Surface roughness of opalescent porcelains after polishing. Oper Dent 1995; 20: 106-10.

18. Çökük N. Effect of different polishing methods on the surface roughness of all ceramic systems. Atatürk Üniv Diş Hek Fak Derg 2009; 19: 98-104.

19. Sasahara RMC, Ribeiro FC, Cesar PH, et al. Influence of the finishing technique on surface roughness of dental porcelains with different microstructures. Oper Dent 2006; 31: 577-583.

20. Oliviera MCS, Vieira AC, Miranda $C B$, et al. The effect of polishing techniques on the surface roughness of a feldspathic porcelain. Rev Odonto Ciênc 2008; 23: 330-2.

21. Fuzzi M, Zaccheroni Z, Vallania G. Scanning electron microscopy and profilometer evaluation of glazed and polished dental porcelain. Int J Prosthodont 1996; 9: 452-8.

22. Boaventura JMC, Nishida $R$, Elossais $A A$, et al. Effect finishing and polishing procedures on the surface roughness of IPS Empress 2 ceramic. Acta Odontologica Scandinavica 2013; 71: 438-43.

23. Bottino MC, Valandro LF, Kantorski KZ, et al. Polishing methods of an alumina-reinforced feldspar ceramic. Braz Dent J 2006; 17: 285-9.

24. Raimondo RL Jr, Richardson JT, Wiedner B. Polished versus autoglazed dental porcelain. J Prosthet Dent 1990; 64: 553-7.

25. Heintze SD, Cavalleri A, Forjanic $M$, et al. Wear of ceramic and antagonist: a systematic evaluation of influencing factors in vitro. Dental Materials 2008; 24: 433-49.

26. Yu HY, Cai ZB, Ren PD, et al. Friction and wear behavior of dental feldspathic porcelain. Wear 2006; 261: 611-21.

27. Rosenstiel SF, Land MF, Fujimoto J. Contemporary Fixed Prosthodontics. 4 ed. St. Louis: Mosby Elsevier, 2006: 901.

28. Larson TD. Why Do We Polish? Part Two. Northwest Dentistry 2011; 90: 31-8.

29. Milleding P, Gerdes S, Holmberg K, et al. Surface energy of non-corroded and corroded dental ceramic materials before and after contact with salivary proteins. Eur J Oral Sci 1999; 107:384-92. 
30. Quirynen M, Marechal M, Busscher HJ, et al. The influence of surface free energy and surface roughness on early plaque formation: An in vivo study in man. J Clin Periodontol 1990; 17: 138-44.

31. Quirynen M. The clinical meaning of the surface roughness and the surface free energy of intraoral hard substrata on the microbiology of the supra and subgingival plaque: results of in vitro and in vivo experiments. J Dent 1994; 22: 13-6.

32. Quirynen $M$, Bollen $C M$. The influence of surface roughness and surface-free energy on supra and subgingival plaque formation in man: a review of the literature. J Clin Periodontol 1995; 22: 1-14.

33. Ahmad R, Morgano SM, Wu BM, et al. An evaluation of the effects of handpiece speed, abrasive characteristics, and polishing load on the flexural strength of polished ceramics. J Prosthet Dent 2005; 94: 421-9.

34. Jung M. Finishing and polishing of a hybrid composite and a heat-pressed glass ceramics. Oper Dent 2002; 27: 175-83.

35. Whitehead SA, Shearer AC, Watts DC, et al. Comparison of methods for measuring surface roughness of ceramic. J Oral Rehabil 1995; 22: 421-7.

36. Kou W, Molin M, Sjögren G. Surface roughness of five different dental ceramic core materials after grinding and polishing. Journal of Oral Rehabilitation 2006; 33: 117-24.

37. Sarikaya I, Güler AU. Effects of different surface treatments on the color stability of various dental porcelains. Journal of Dental Sciences 2011; 6: 6571.

\section{Yazışma Adresi:}

Dt. Faruk EMİR

GATA Diş Hekimliği Bilimleri

Merkezi Protetik Diş Tedavisi Anabilim Dalı

06010/ANKARA

Telefon: 03123041425

E-posta: emirfaruk@gmail.com 